\title{
Electrospun Carbon Nanofiber Membranes for Filtration of Nanoparticles from Water
}

\author{
Mirko Faccini, Guadalupe Borja, Marcel Boerrigter, \\ Diego Morillo Martín, Sandra Martìnez Crespiera, Socorro Vázquez-Campos, \\ Laurent Aubouy, and David Amantia
}

LEITAT Technological Center, C/de la Innovació 2, 08225 Terrassa, Spain

Correspondence should be addressed to Mirko Faccini; mfaccini@leitat.org

Received 13 October 2014; Accepted 12 December 2014

Academic Editor: Fujuan Liu

Copyright (C) 2015 Mirko Faccini et al. This is an open access article distributed under the Creative Commons Attribution License, which permits unrestricted use, distribution, and reproduction in any medium, provided the original work is properly cited.

Nowadays, hundreds of consumer products contain metal and metal oxide nanoparticles (NP); this increases the probability of such particles to be released to natural waters generating a potential risk to human health and the environment. This paper presents the development of efficient carboneous nanofibrous membranes for NP filtration from aqueous solutions. Free-standing carbon nanofiber (CNF) mats with different fiber size distribution ranging from 126 to $554 \mathrm{~nm}$ in diameter were produced by electrospinning of polyacrylonitrile (PAN) precursor solution followed by thermal treatment. Moreover, tetraethoxyorthosilicate was added to provide flexibility and increase the specific surface area of the CNF. The resulting membranes are bendable and mechanically strong enough to withstand filtration under pressure or vacuum. The experimental results of filtration revealed that the fabricated membranes could efficiently reject nanoparticles of different types $\left(\mathrm{Au}, \mathrm{Ag}\right.$, and $\left.\mathrm{TiO}_{2}\right)$ and size (from 10 to $100 \mathrm{~nm}$ in diameter) from aqueous solutions. It is worth mentioning that the removal of Ag NP with diameters as small as $10 \mathrm{~nm}$ was close to $100 \%$ with an extremely high flux of $47620 \mathrm{~L} \mathrm{~m}^{-2} \mathrm{~h}^{-1} \mathrm{bar}^{-1}$.

\section{Introduction}

Nanotechnology is having a large impact in manufactured products in most major industry sectors, including electronic, cosmetic, automotive, and healthcare sectors. According to a recent survey [1] over 1,300 nanotechnology-related products are currently on the market. Free nanoparticles (NP) are likely to enter the aquatic environment in all stages of nanomaterials life cycle (production, processing, use, recycling, and disposal). These particles can persist in natural bodies and are not fully removed by drinking water treatment systems, thereby posing a potential public health concern $[2,3]$. Therefore, the development of new barrier materials is needed to reduce the potential risks related to human and environmental exposure to nanomaterials [4]. Nanofiber webs, due to their very large specific area, very small pore size, and high porosity, have been shown to improve the efficiency of conventional materials used for the filtration and separation of particulate materials $[5,6]$.
Electrospinning is a well-established and versatile process that has been used to produce ultrafine fibers including microfibers $(>1 \mu \mathrm{m})$ or nanofibers $(<1000 \mathrm{~nm})[7,8]$. The main advantage of electrospinning process among other techniques is the relative quick, simple, and economical way to fabricate a variety of materials into nanofibrous structures [9].

Particularly, electrospun carbon nanofibers (CNF) have attracted considerable attention in the field of water filtration as they exhibit a number of unique features [10]. While the development of free-standing ceramic nanofibrous mats is still a technological challenge due to the intrinsic brittleness of the material, large area CNF sheets with high mechanical strength can be easily fabricated. In addition, their higher chemical resistance, compared to polymeric filters, makes them suitable for filtration $[11,12]$.

In this study, the development of efficient nanofiber membranes for the removal of nanoparticles from aqueous solutions is presented. Free-standing carbon nanofibrous 
membranes were fabricated by electrospinning of a polyacrylonitrile (PAN) precursor solution followed by a thermal treatment of the electrospun fibers. Moreover, tetraethoxyorthosilicate (TEOS) was added to provide flexibility and to increase the specific surface area of the CNF $[13,14]$.

To the best of our knowledge, CNF derived from PAN/TEOS have not been used for such filtration purposes. Unlike carbonized PAN mats, which were too brittle to tolerate high vacuum filtration process, the PAN/TEOS derived CNF mats were bendable and showed sufficient mechanical strength to withstand filtration under pressure or vacuum. The experimental results demonstrate that the membranes could efficiently reject various $\mathrm{NP}\left(\mathrm{Au}, \mathrm{Ag}\right.$, and $\left.\mathrm{TiO}_{2}\right)$ of different sizes and natures from the aqueous solution.

\section{Experimental Part}

2.1. Materials and Methods. PAN (Mw $=150,000 \mathrm{~g} / \mathrm{mol})$ powder, $N$-N dimethylformamide (DMF), and TEOS (98\%) were purchased from Sigma-Aldrich. CNF precursor solutions were prepared by dissolving $\mathrm{PAN}$ at concentrations ranging from 4 to 12 wt. $\%$ in $\mathrm{DMF}$ at $60^{\circ} \mathrm{C}$. PAN/TEOS precursor solutions were prepared by the addition of TEOS to the PAN solutions in DMF to achieve the proper PAN/TEOS weight ratios, as shown in Table 2 . All polymer solutions were mixed by a magnetic stirrer for a sufficiently long time until they became homogeneous. The viscosity and electrical conductivity of polymer solutions were measured by a digital viscometer (DV-E, Brookfield Co.) and an electric conductivity meter (CRISON EC-meter BASIC) at $25^{\circ} \mathrm{C}$. To produce nanofibers the solutions were electrospun onto an aluminum foil by using commercially available electrospinning equipment (MECC Co. LTD., model NF-103). Plastic syringes fitted with metal needles were used as electrospinning nozzles. Typical operating conditions were the following: flow rates of 1-2 $\mathrm{mL} / \mathrm{h}$, applied voltages between 25 and $30 \mathrm{kV}$, and working distance of 9-16 cm. For carbonization, the as-spun polymer fibers were first placed in a chamber furnace and stabilized in air for 5 hours at $280^{\circ} \mathrm{C}$ and then carbonized for 1 hour in nitrogen at $800-1000^{\circ} \mathrm{C}$; in both cases the ramp rate was $1^{\circ} \mathrm{C} / \min [15]$.

2.2. Preparation of the NP Solutions. The filtration performance of carbonized PAN/TEOS nanofibers was evaluated with different types of NP, including metallic NP, such as Ag and $\mathrm{Au}$, and metal oxide $\mathrm{NP}$, such as $\mathrm{TiO}_{2} \cdot \mathrm{TiO}_{2}$ dispersions were prepared by the sonication of proper amounts of NP in milliQ water for $10 \mathrm{~min}$ at $50 \%$ of the total power $(750 \mathrm{~W})$. $\mathrm{Au}$ and $\mathrm{Ag}$ aqueous nanoparticle solutions were kindly provided by ICN (Catalonia Institute of Nanotechnology). The concentrations of the NP solutions were adjusted to have a high ultraviolet-visible (UV-vis) absorbance without signal saturation.

2.3. Characterization. The surface morphology of the nanofiber mats was examined using scanning electron microscopy (SEM, Zeiss Evo MA-10) after coating with carbon to minimize the charging effect. Images taken by the SEM were analyzed to obtain the fiber diameter by the ImageJ software. At least four pictures were used to calculate the mean values of the diameter of the fibers.

The clean water permeance (CWP) of CNF membranes was determined using a bench-scale dead-end filtration setup. The system consists of a reservoir tank containing ultrapure water (Type 1) connected to a $200 \mathrm{~mL}$ Amicon stirred ultrafiltration cell (Merck Millipore). The stirred cell houses a $63.5 \mathrm{~mm}$ diameter flat CNF sheet with an effective area of $28.7 \mathrm{~cm}^{2}$. Pressure in the feed tank was provided by compressed air. The applied pressure measured during the CWP experiments was $3 \mathrm{kPa}(0.43 \mathrm{psi})$.

The pore size of the CNF membranes was determined using a simple particle removal method. Solutions containing $20 \mathrm{mg} / \mathrm{L}$ of polystyrene latex beads (from Magsphere Corp.) with diameter between $0.1 \mu \mathrm{m}$ and $3 \mu \mathrm{m}$ were passed through the membrane at the pressure of about 0.1 bar. The absorbance of the feed and filtrate latex solutions was measured using UV-vis spectrometer and the removal rate was calculated by the following formula, where $A_{\text {feed }}$ and $A_{\text {filtrate }}$ are the absorbance at $250 \mathrm{~nm}$ of feed and filtrate solutions, respectively:

$$
\text { Removal rate } \%=\left[1-\left[\frac{A_{\text {feed }}}{A_{\text {filtrate }}}\right]\right] * 100 .
$$

A latex removal curve was drawn by plotting the removal rates against the beads diameter size (Figure 7). The nominal pore size is defined as the diameter where $90 \%$ of latex beads are removed.

For filtration experiments, disc filter was cut out of the nanofibrous mats by using a hollow punch and placed on the metallic support of the filtration setup. A solution of nanoparticles was passed through it and UV-vis spectrometer was used to measure the absorbance of the feed and filtrate solutions. The filtration efficiency was calculated using the following formula, where $A_{\text {feed }}$ and $A_{\text {filtrate }}$ are the absorbance at $\lambda_{\max }$ of feed and filtrate solutions, respectively:

$$
\text { Filtration efficiency } \%=\left[\frac{\left[A_{\text {feed }}-A_{\text {filtrate }}\right]}{A_{\text {feed }}}\right] * 100 \text {. }
$$

\section{Result and Discussion}

3.1. CNF Membranes. It is known that the morphology of electrospun fibers depends on various processing parameters, solution properties, and environmental conditions. Through control of the spinning conditions, the resulting fibers can range from about $20 \mathrm{~nm}$ to a few micrometers. To gain control over the properties of the obtained nanofibers, the viscosity and conductivity were measured as a function of the PAN concentration. Figure 1 shows an overlay plot of the viscosity and conductivity as function of the PAN weight percentage in DMF. By increasing the PAN concentration from 4 to $12 \mathrm{wt} . \%$ the viscosity rises exponentially from 31 to $2053 \mathrm{cP}$, as a result of the higher molecular entanglement. In fact, at higher precursor concentration the polymer chains are more tangled, which leads to the production of broader fibers. The electric conductivity also increases from 48 to $86 \mu \mathrm{s} / \mathrm{cm}$ by 
TABLE 1: Process parameters used for the electrospinning of solutions C-1 to C-5 and the average diameters of the PAN nanofibers and CNF mats.

\begin{tabular}{lccccccc}
\hline Solution code & $\begin{array}{c}\text { PAN } \\
(\text { wt. } \%)\end{array}$ & $\begin{array}{c}\text { Feed rate } \\
(\mathrm{mL} / \mathrm{h})\end{array}$ & $\begin{array}{c}\text { Voltage } \\
(\mathrm{kV})\end{array}$ & $\begin{array}{c}\text { Distance } \\
(\mathrm{cm})\end{array}$ & $\begin{array}{c}\text { Applied electric field } \\
(\mathrm{kV} / \mathrm{cm})\end{array}$ & $\begin{array}{c}\text { PAN nanofibers diameter } \\
(\mathrm{nm})\end{array}$ & $\begin{array}{c}\text { Carbon nanofibers diameter } \\
(\mathrm{nm})\end{array}$ \\
\hline C-1 & 4 & 2 & 30 & 7 & 4.2 & $96 \pm 24$ & - \\
C-2 & 6 & 2 & 30 & 10 & 3.0 & $189 \pm 47$ & $126 \pm 19$ \\
C-3 & 8 & 2 & 29 & 13 & 2.2 & $282 \pm 51$ & $184 \pm 31$ \\
C-4 & 10 & 2 & 29 & 15 & 1.9 & $351 \pm 78$ & $249 \pm 24$ \\
C-5 & 12 & 2 & 27 & 16 & 1.7 & $620 \pm 39$ & $554 \pm 107$ \\
\hline
\end{tabular}

TABLE 2: Characterization of the PAN/TEOS solutions C-Si-1 to C-Si-3 and the average diameters of the PAN/TEOS nanofibers and CNF/Si mats.

\begin{tabular}{lcccccc}
\hline Solution code & $\begin{array}{c}\text { PAN } \\
(\text { wt. } \%)\end{array}$ & $\begin{array}{c}\text { PAN/TEOS } \\
(\mathrm{w} / \mathrm{w})\end{array}$ & $\begin{array}{c}\text { Viscosity } \\
(\mathrm{cP})\end{array}$ & $\begin{array}{c}\text { Conductivity } \\
(\mu \mathrm{s} / \mathrm{cm})\end{array}$ & $\begin{array}{c}\text { PAN/TEOS nanofibers diameter } \\
(\mathrm{nm})\end{array}$ & $\begin{array}{c}\text { CNF/Si diameter } \\
(\mathrm{nm})\end{array}$ \\
\hline C-Si-1 & 6 & $7 / 3$ & 132 & 96 & $244 \pm 31$ & $158 \pm 38$ \\
C-Si-2 & 8 & $7 / 3$ & 285 & 93 & $300 \pm 33$ & $193 \pm 36$ \\
C-Si-3 & 10 & $7 / 3$ & 647 & 102 & $487 \pm 65$ & $387 \pm 33$ \\
\hline
\end{tabular}

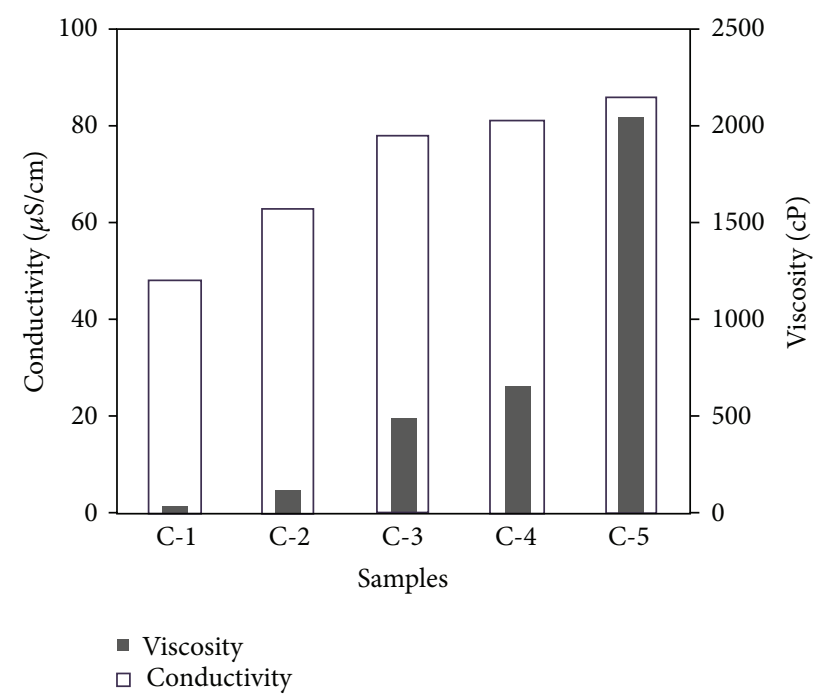

FIGURE 1: Solution viscosity and electrical conductivity as function of the polymer solution concentration.

increasing the concentration from 4 to $12 \mathrm{wt} \%$. As shown in Table 1, for each solution, different operating conditions were set to produce nanofibers in a continuous and stable electrospinning process. When the electrical conductivity of the solution was higher, a lower electrical field (voltage/distance) was needed for the formation of nanofibers. For example, for solution C-1, having the lowest viscosity of $31 \mathrm{cP}$, the electrospinning process was not sufficiently stable, and a high voltage had to be applied to form fibers. In fact, the fibers were formed by the application of the highest electrical field, and this led to the formation of beads and defects. Moreover, solution C-5, with a polymer concentration of $12 \mathrm{wt} . \%$, although it possessed the highest viscosity of $2053 \mathrm{cP}$, could be electrospun by the application of the lowest electrical field. This means that the most critical parameter to be controlled for a continuous and stable process is the solution conductivity. For instance, at low conductivities, the addition of salts is commonly used to improve process stability [16]. The SEM micrographs and diameter distribution of PAN nanofibers as function of polymer concentration are shown in Figure 2. The average fiber diameter increases gradually with polymer concentration going from $189 \mathrm{~nm}$ at $6 \mathrm{wt} . \%$ to $620 \mathrm{~nm}$ at $12 \mathrm{wt} . \%$. This indicates that the morphology of the nanofibers depends on polymer concentration which effects viscosity. At higher viscosity there are more chain entanglements and less chain mobility, resulting in less extension during spinning, therefore producing thicker fibers.

The pyrolysis process of PAN based nanofibers generally consists of stabilization process in air followed by carbonization at higher temperatures in inert atmosphere. The optimal stabilization temperature for PAN has been reported to be around $280^{\circ} \mathrm{C}$; at this temperature several reactions, that is, cyclization, dehydrogenation, aromatization, and oxidation, take place, which generates the formation of conjugated ladder-type structures [15]. These structures are thermally stable and might be able to withstand high temperature to prevent melting of the polymer and loss of nanofiber morphology during carbonization. Moreover, stabilization changes the color of PAN nanofibrous mats from white to brown. The trend of color change from light to dark results from the increment of carbon content and formation of dense structure of polymer in thermal cyclization and dehydrogenation. Large area CNF mats could be obtained after the thermal treatment process. These sheets, however, were quite rigid and could be easily broken by manipulation or bending.

Figure 3 shows the SEM micrographs and diameter distribution of the CNF after the thermal treatment of the asspun nanofibers at different concentrations. As expected, remarkable weight loss and shrinkage occurred during the carbonization of the PAN fibers. However, the heat-treated fibers were still long and retained their cylindrical and uniform shape. In fact, at high temperatures, some small molecules may have broken down into highly volatile gases 

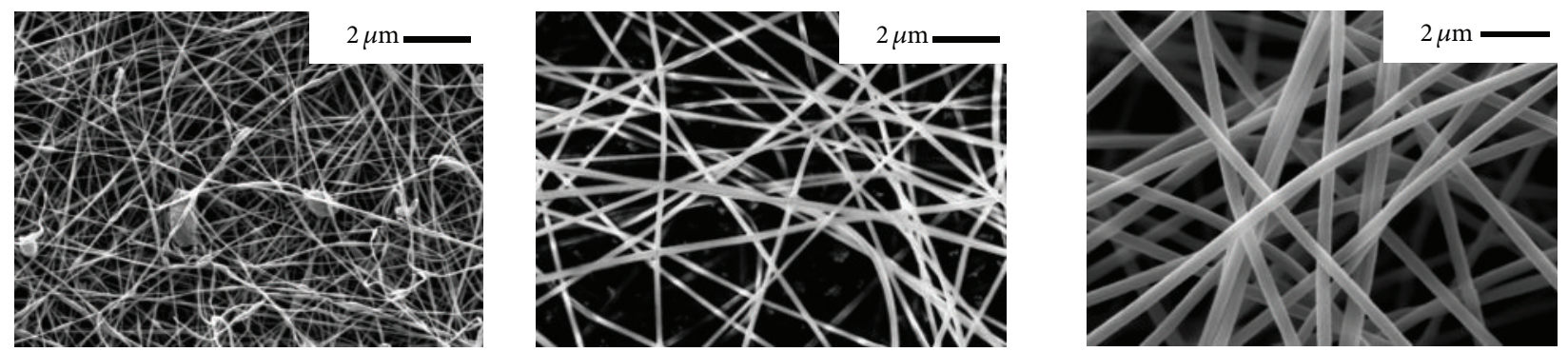

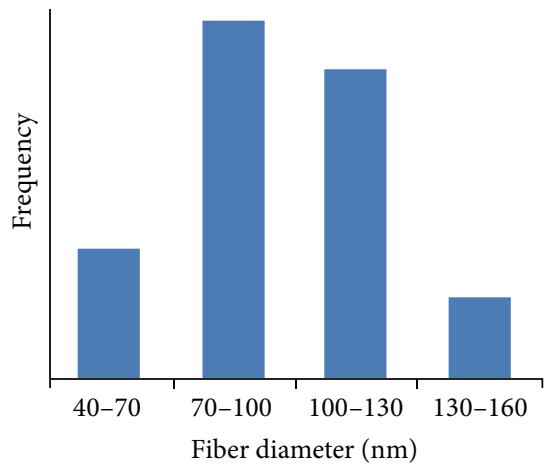

(a)

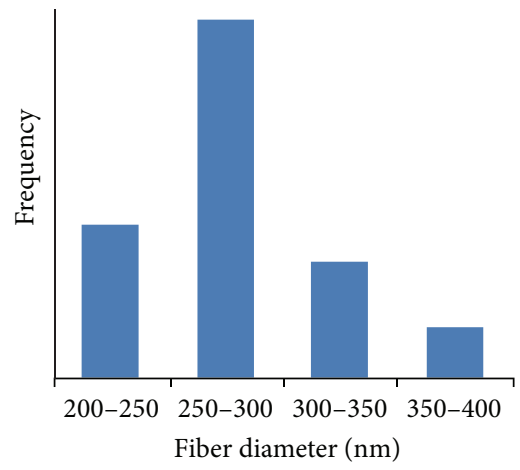

(b)

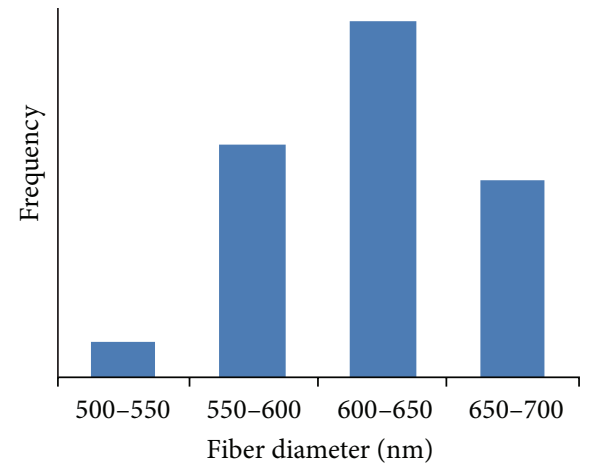

(c)

FIGURE 2: SEM images and diameter distribution of nanofibers obtained by electrospinning PAN solutions C-1 (a), C-3 (b), and C-5 (c).
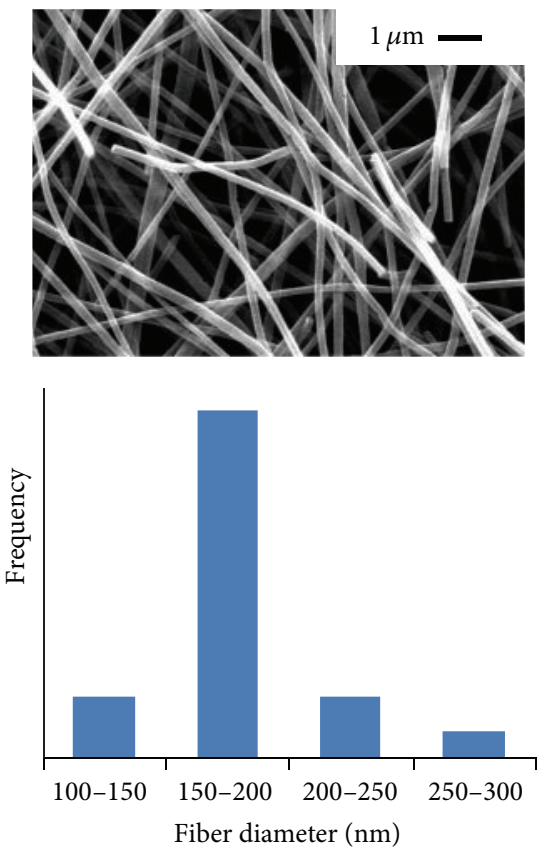

(a)
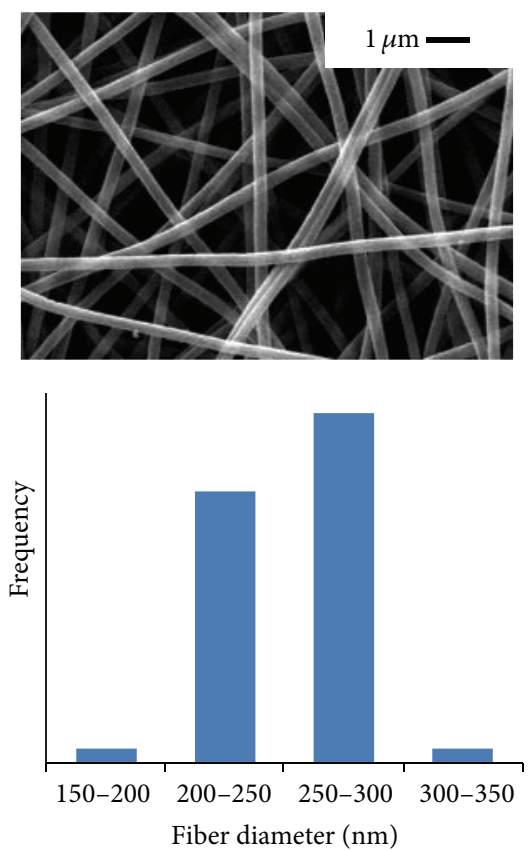

(b)
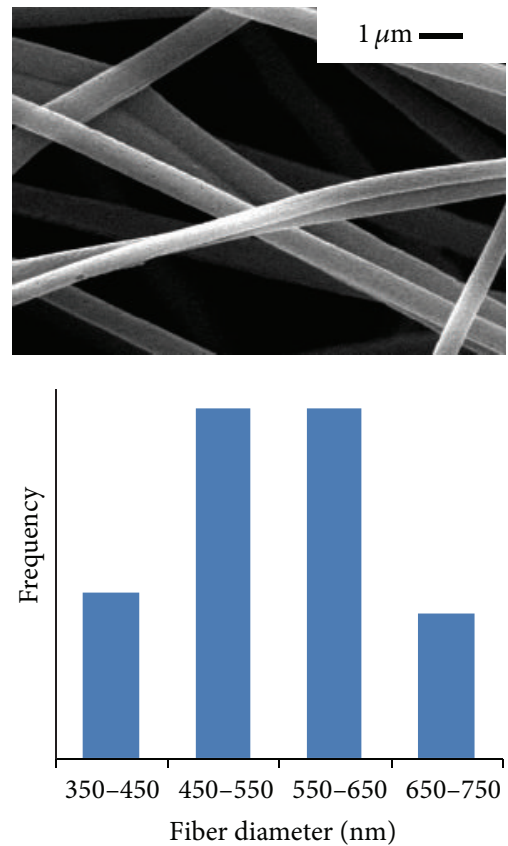

(c)

FIGURE 3: SEM images and diameter distribution of the CNF obtained by the thermal treatment of the as-spun nanofibers of the PAN solutions: (a) C-3, (b) C-4, and (c) C-5.

or carbon char. In addition, during the carbonization, the disruption of the molecules occurred with the loss of carbon oxides and the formation of a structure with a higher carbon assay, which resulted in significant weight loss and shrinkage. In other words, when the PAN nanofibrous mats are subjected to the stabilization temperature, the dense ladder-polymer structures react with oxygen and prevent melting during carbonization. The carbonization process of stabilized PAN mats involves thermal treatment to remove noncarbon elements. Then, denitrogenation takes place and thus results in the formation of a network structure [17]. 


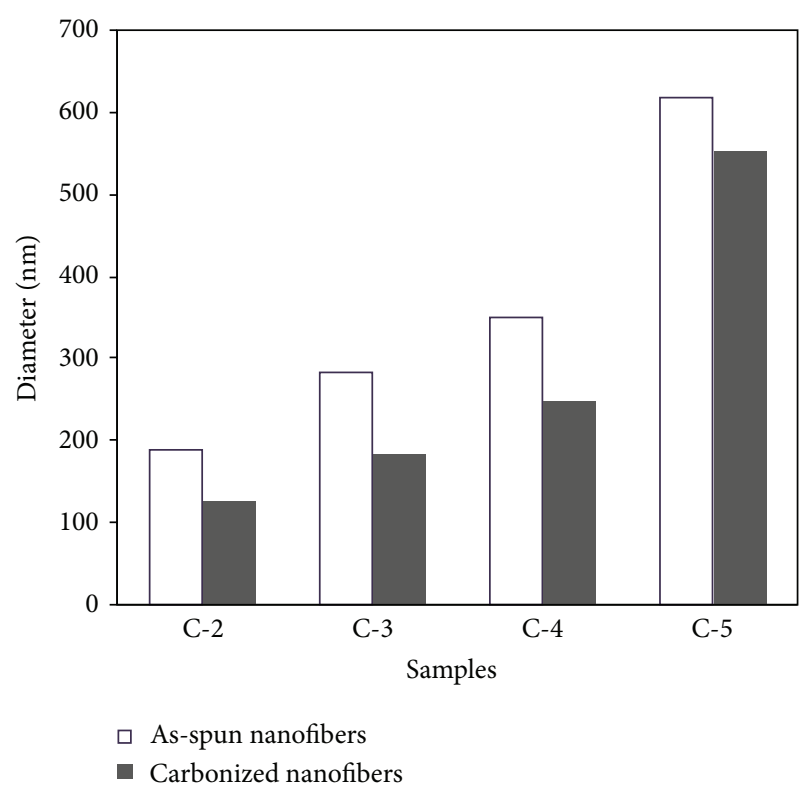

Figure 4: Average fiber diameter of as-spun and carbonized nanofibers.

A comparison between the average fiber diameters of the as-spun and carbonized nanofibers is presented in Figure 4. The as-spun nanofibers thermally treated at $800^{\circ} \mathrm{C}$ shrink in diameter and lose approximately $25-30 \%$ of their weight. In this step, the CNF mats with fiber diameters ranging from 126 to $554 \mathrm{~nm}$ were successfully obtained. However, because of the rigidity of the CNF, a more flexible material was needed to reduce any potential accidental damage of the membrane that might occur during filtration generating preferential pathways for contaminants and consequently loss of retention capacity.

3.2. CNF/Si Membrane. Recently, Kim et al. [13] reported the fabrication of flexible CNF mats by the incorporation of TEOS into PAN via electrospinning for supercapacitor electrodes. They also concluded that the new mats had high capacitance and energy/power density values because of the formation of ultramicropores and the introduction of heteroatoms. We hypothesized that the same approach could be successfully applied to produce flexible CNF mats with high surface areas for NP filtration from aqueous solutions. For this purpose, different solutions were prepared by varying of the concentration of PAN in DMF (C-Si-1, C-Si-2, and C-Si-3), as shown in Table 2. For the PAN/TEOS solutions presented in this table, the optimum concentrations of PAN (obtained from Table 1) were chosen to produce the CNF/Si mats. TEOS was added to the PAN solutions on the basis of a specific ratio of $3: 7$, respectively. According to data reported in the literature [14], through the application of this specific ratio of PAN/TEOS, the highest mesoporous structures could be formed, and this could enhance the filtration efficiency of the fibers. As described in the previous section for the CNF, the average fiber diameter grew gradually with the polymer concentration.
In fact, at a constant PAN/TEOS weight ratio, the fiber diameter went from $244 \mathrm{~nm}$ at $6 \mathrm{wt}$.\% PAN (for the solution of C-Si-1) to $487 \mathrm{~nm}$ when the concentration was $10 \mathrm{wt}$.\% (for the solution of C-Si-3). The PAN/TEOS mats were thermally treated with the stabilization-calcination procedure previously described. The diameter of the carbonized PAN/TEOS nanofibers $(\mathrm{CNF} / \mathrm{Si})$ after carbonization at $800^{\circ} \mathrm{C}$ reduced roughly to $35 \%$ of its initial diameter regardless of the PAN concentration in DMF (see Table 2) [18].

To investigate the effect of higher carbonization temperatures on the fiber morphology, the PAN/TEOS nanofibers were also carbonized at $1000^{\circ} \mathrm{C}$. It is notable that stabilization is critical in obtaining morphological stability. These kinds of oxidative stabilizations include complex chemical reactions and time-consuming steps. It was reported previously that the stabilization processes of TEOS-incorporated nanofibers were kinetically higher than those of pure polymeric electrospun nanofibers because of the catalytic ability of TEOS [14]. The trapped TEOS in the nanofibers could be transformed into hydrated forms. During the stabilization process, silanol $\left[\mathrm{Si}(\mathrm{OH})_{x}\right]$ groups tended to be produced by sequence hydrolysis reactions. Further condensation of $\mathrm{Si}-\mathrm{OH}$ led to the formation of $\mathrm{SiO}_{x}$ and to gas formation (e.g., $\mathrm{CO}, \mathrm{CO}_{2}, \mathrm{H}_{2}$, $\mathrm{CH}_{4}$, and $\mathrm{H}_{2} \mathrm{O}$ ). Figure 5 shows the SEM micrographs and diameter distribution diagrams of CNF/Si after the thermal treatment of the as-spun nanofibers produced by the solution C-Si-3 at 800 and $1000^{\circ} \mathrm{C}$. As shown, all of the resulting samples were smooth and exhibited cylindrical morphologies. The average diameter of the nanofibers decreased from 487 to $387 \mathrm{~nm}$ and then to $289 \mathrm{~nm}$ as the carbonization temperature increased from 800 to $1000^{\circ} \mathrm{C}$. Moreover, when the nanofibers were thermally treated at temperatures greater than $800^{\circ} \mathrm{C}$, a color change from brownish black to black was observed due to a higher percentage of graphite [19].

The resulting CNF/Si mats showed good robustness and were more flexible than the CNF mats obtained by the thermal treatment of PAN. In addition, no broken fibers were visible; this indicated that the mats were exceptionally strong with long nanofibers having diameters ranging from 158 to $387 \mathrm{~nm}$ (see Table 2 ). The observations indicated that the CNF/Si membranes are mechanically strong enough and they can be bent completely without breaking (Figure 6). The robustness of the CNF/Si membranes and the ability to be produced in an easy and cost-efficient way by electrospinning make these carbonaceous nanofibers potential candidates for the filtration of NP from aqueous solutions.

3.3. Pore Size and Water Flux. Nanofiber membranes have been shown to provide dramatic increases in filtration efficiency at relatively small reduction in permeability [20]. Moreover, in many laboratory tests and actual operating environments, nanofiber filter media have also enabled new levels of filtration performance and more capacity to retain pollution compared to traditional fibers thanks to their open porous structure. Several methods have been used for pore size measurement of nanofibrous membranes [21]. Each of them has different measuring theory and it is often seen that 

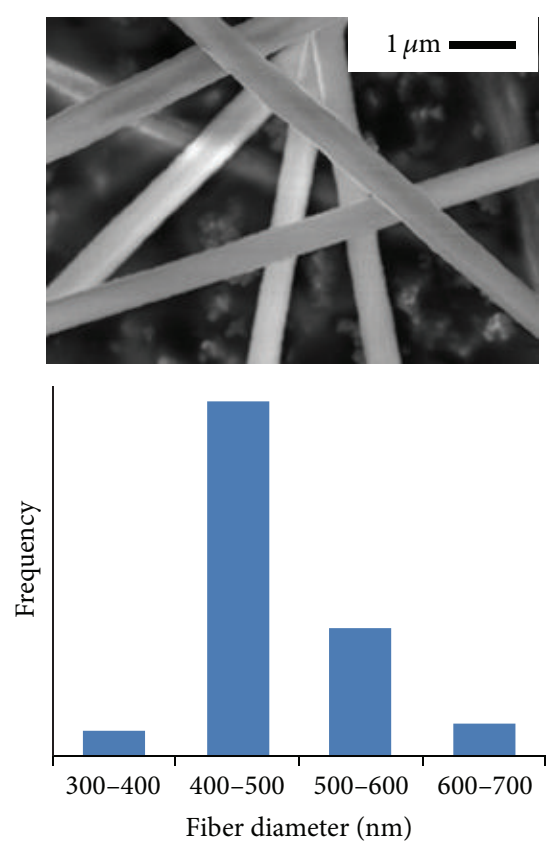

(a)
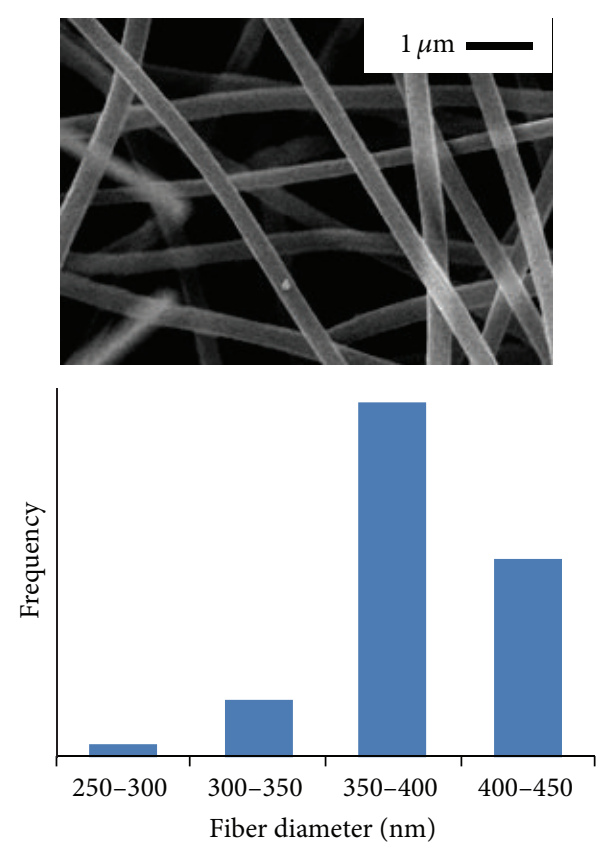

(b)
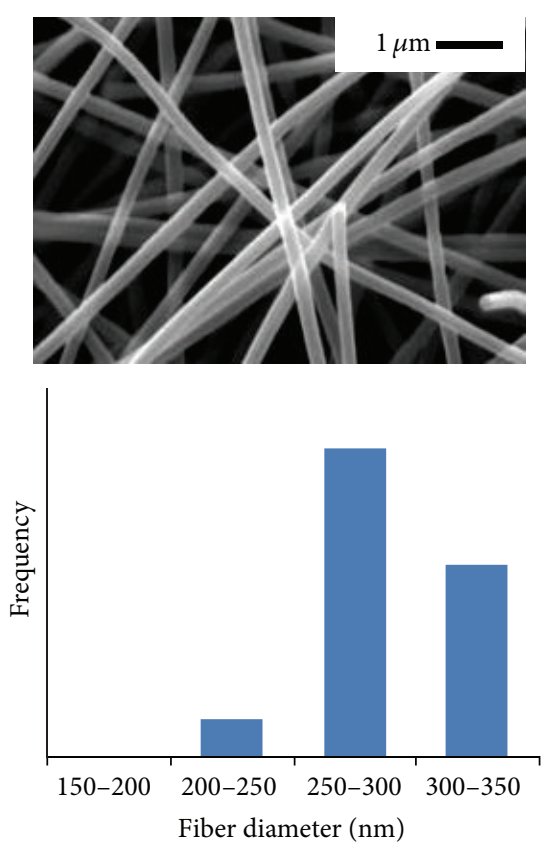

(c)

Figure 5: SEM images and diameter distribution of the (a) PAN/TEOS nanofiber mats and CNF/Si obtained by the thermal treatment of the as-spun PAN/TEOS nanofibers of solution C-Si-3 at (b) $800^{\circ} \mathrm{C}$ and (c) $1000^{\circ} \mathrm{C}$.

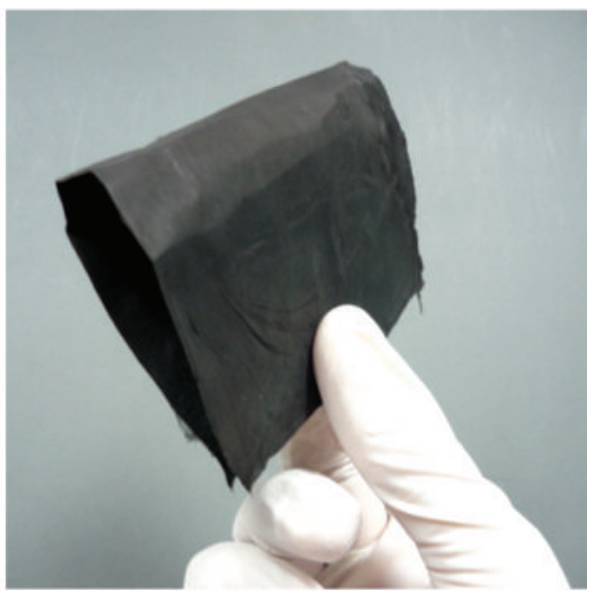

FIGURE 6: Digital picture showing the flexibility of the CNF/Si mats.

different results are obtained by measurement of the same membrane using different methods.

In this study, the nominal pore size of CNF/Si membrane is determined using a simple method based on the filtration of latex beads of well-established size. The graph in Figure 7 shows that the CNF/Si membrane was able to retain almost completely particles of approximately $1 \mu \mathrm{m}$ or larger, resulting in an extrapolated nominal pore size of $0.8 \mu \mathrm{m}$. Polystyrene beads of different sizes trapped on the surface of the nanofiber filter are clearly visible in the SEM image of Figure 7. Although most of the $1 \mu \mathrm{m}$ beads and larger are trapped onto the membrane top surface, smaller beads are visible not only onto the membrane surface but also throughout the whole membrane section.

As consequence of the large porosity and the hydrophilicity, the $\mathrm{CNF} / \mathrm{Si}$ membrane possesses an extremely large water flux of $47620 \mathrm{~L} \mathrm{~m}^{-2} \mathrm{~h}^{-1} \mathrm{bar}^{-1}$. This is almost 4 times higher than the carbonaceous nanofiber membranes recently reported by Liang et al., which were $12250 \mathrm{~L} \mathrm{~m}^{-2} \mathrm{~h}^{-1}$ bar $^{-1}$ and 80 times higher than commercially available membranes with cut-off of $0.05 \mu \mathrm{m}$ being $757 \mathrm{~L} \mathrm{~m}^{-2} \mathrm{~h}^{-1} \mathrm{bar}^{-1}$ [22]. This difference is due to the low porosity of the commercially available membranes and the low porosity of vertical cylindrical channels which can easily get blocked by particles [22, 23].

3.4. Filtration of Aqueous NP Dispersions. Recently, Lin et al. [24] reported the preparation of a mechanically robust and thermally tolerant nanofibrous membrane via electrospinning of Nomex solution. They concluded that the preparation of membranes in the form of nanofibers dramatically enhanced the specific surface area of the membranes compared to the commercial Nomex fibers. In addition, their nanofibrous membranes demonstrated a highly efficient rejection of $\mathrm{SiO}_{2}$ NP from aqueous solution. This observation significantly proved the high potential of polymeric nanofibers for filtration due to their larger surface area. Here, the membranes produced by the carbonization at $1000^{\circ} \mathrm{C}$ of electrospun nanofibers from solution C-Si-3 were initially used to assess the filtration ability of $\mathrm{CNF} / \mathrm{Si}$ mats. The filtration performance of the $\mathrm{CNF} / \mathrm{Si}$ membrane was evaluated with different types of NP, including metal NP, such as $\mathrm{Au}$ and $\mathrm{Ag}$, and metal oxide NP, such as $\mathrm{TiO}_{2}$. 


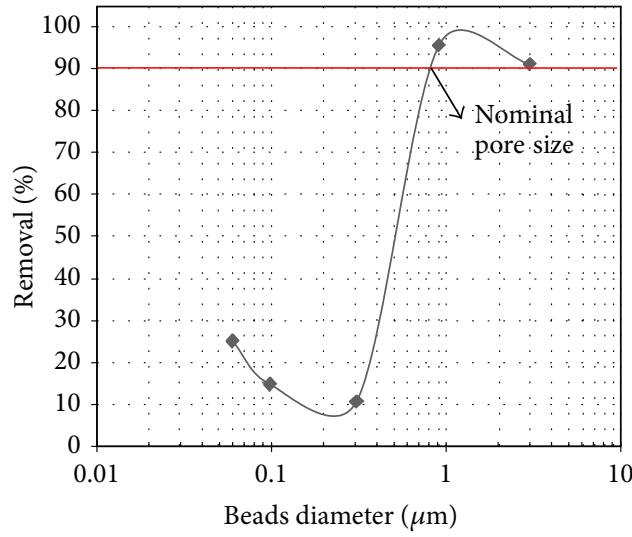

(a)

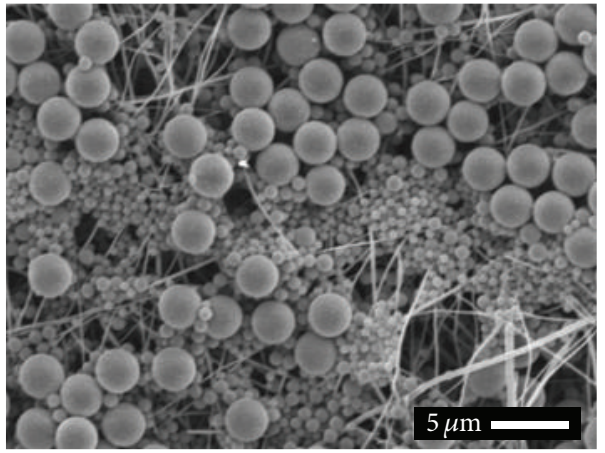

(b)

FIGURE 7: Latex beads removal percentage curve as function of beads diameter for CNF/Si membrane (a) and SEM image of the CNF/Si membrane top surface after filtration with beads with diameter going from $0.1 \mu \mathrm{m}$ to $3 \mu \mathrm{m}$ (b).

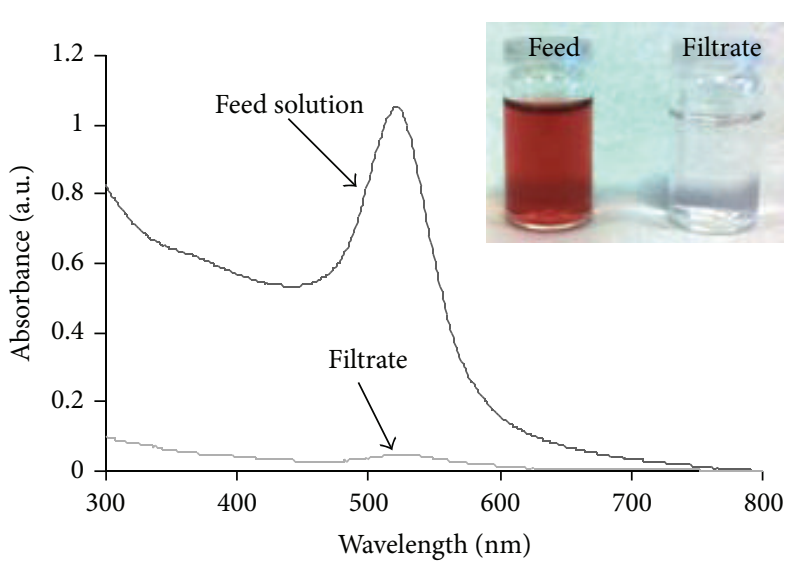

(a)

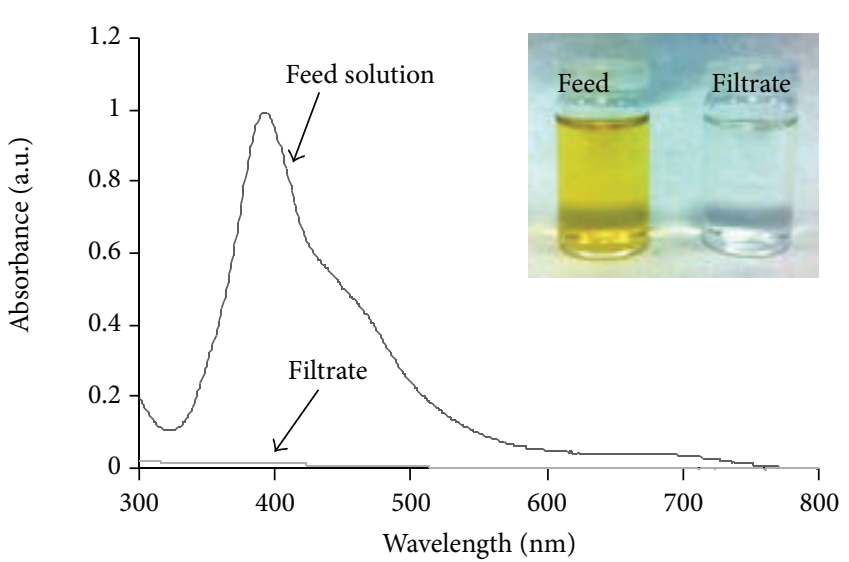

(c)

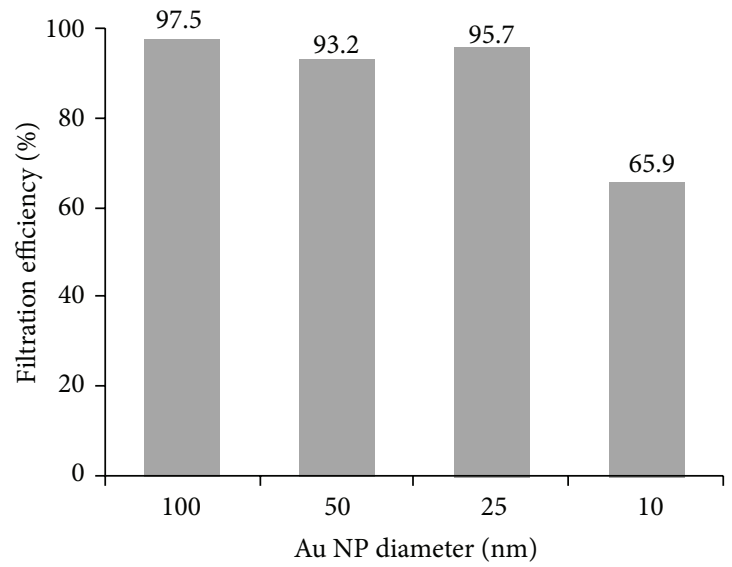

(b)

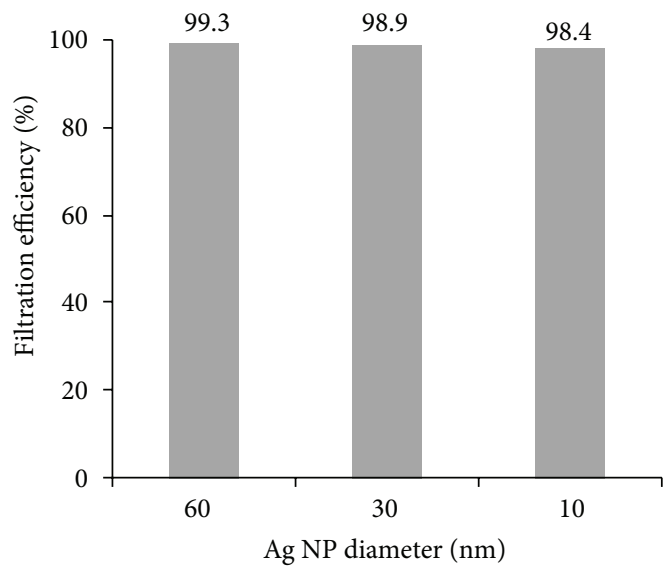

(d)

FIGURE 8: UV-vis spectra of feed solution and filtrate showing the filtration of Au NP (a) and Ag NP (c) and the filtration efficiency as function of particle size for Au NP (b) and Ag NP (d). 


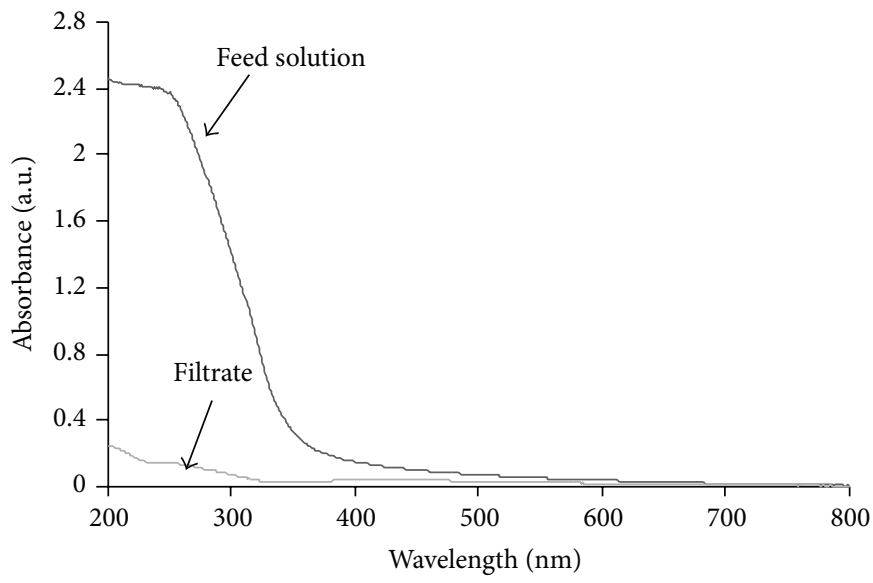

(a)

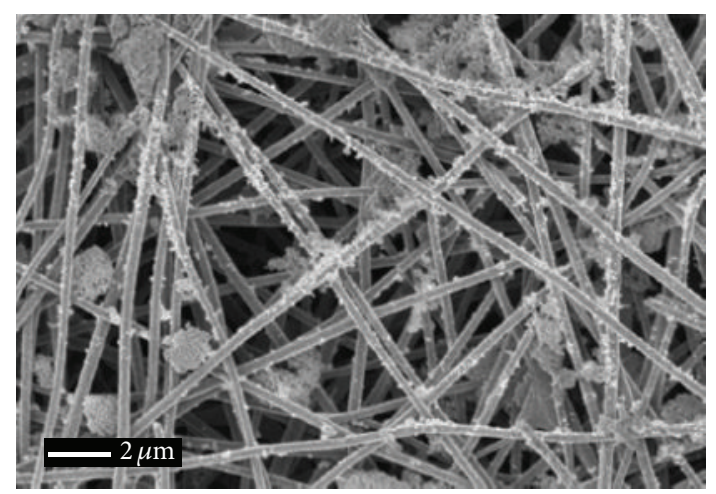

(b)

FIGURE 9: UV-vis spectra of feed solution and filtrate showing the filtration of $\mathrm{TiO}_{2} \mathrm{NP}$ (a) and SEM image of top surface of the CNF/Si membrane after filtration with $\mathrm{TiO}_{2} \mathrm{NP}(\mathrm{b})$.

Metal NP visualization of the filtration can easily be achieved by following the characteristic intense color that is yellow for Au NP and red for Ag NP dispersions. In the case of the Au NP solutions, the filtration efficiency was determined by measurement of the absorption at $\lambda_{\max }$ in the range 520-540 $\mathrm{nm}$ of the feed and filtrate solutions using NP with diameter of $100,50,25$, and $10 \mathrm{~nm}$. As an example, a typical UV-vis spectrum is shown in Figure 8, as well as the retention as function of NP size. The nanostructured $\mathrm{CNF} / \mathrm{Si}$ filters were able to retain about $95 \%$ of the Au NP of 100 , 50 , and $25 \mathrm{~nm}$. However, when smaller NP were used, the filtration efficiency dropped to about $66 \%$ for the $10 \mathrm{~nm}$ NP.

For the Ag NP dispersions, the UV-vis absorption at $\lambda_{\max }$ values around $400-420 \mathrm{~nm}$ was used, and solutions with NP of average diameters of 60,30 , and $10 \mathrm{~nm}$ were used. As shown in Figure 8, the nanofibrous membranes could almost completely remove the Ag NP regardless of their particle sizes. In fact, for all three NP sizes, the retention was around $99 \%$. Interestingly, in contrast to what was observed for the $\mathrm{Au}$ NP, in this case, the filtration efficiency did not decrease when smaller NP (e.g., $10 \mathrm{~nm}$ ) were used.

The demand of $\mathrm{TiO}_{2} \mathrm{NP}$ is significantly increasing due to its wide range of applications such as environmental technologies, paints, cosmetics, paper, and solar cells [25]. The world production of $\mathrm{TiO}_{2} \mathrm{NP}$ is an order of magnitude greater than the next most widely produced nanomaterial, $\mathrm{ZnO}$. $\mathrm{TiO}_{2}$ may reach high concentrations in surface waters and pose a significant threat to aquatic ecosystems [26]. Therefore, here, the filtration efficiency of CNF/Si membranes against dispersions of $\mathrm{TiO}_{2} \mathrm{NP}$ with average diameter of $10-15 \mathrm{~nm}$ in water is examined. The UV-vis spectra of the feed solution and filtrate are shown in Figure 9. The filtration efficiency for the $\mathrm{TiO}_{2} \mathrm{NP}$ was very high, being $94.1 \%$. Figure 9 (b) shows the typical SEM micrograph of the top surface of the CNF/Si membrane after filtration of the $\mathrm{TiO}_{2} \mathrm{NP}$ solution.

Small and large NP aggregates are clearly visible on the surface of single nanofibers. The SEM image evidencing that the pore size of the nanofiber filter is too large to retain NP based on sieving model. Therefore, the high NP retention capacity of the membrane might be attributed to strong electrostatic interaction of metal and metal oxide NP with the $\mathrm{CNF} / \mathrm{Si}$ membranes resulting in a good retention capacity of the filters.

\section{Conclusion}

CNF membranes were fabricated by the electrospinning of PAN precursor solutions followed by the thermal treatment of the electrospun fibers. TEOS was added to the polymer solution to increase the specific surface area of the CNF and to provide flexibility and mechanical strength needed to withstand filtration under pressure or vacuum. These developed filters were capable of efficiently rejecting NP of different sizes and natures (e.g., $\mathrm{Au}, \mathrm{Ag}$, and $\mathrm{TiO}_{2}$ ) from aqueous solution. The results described herein demonstrate the great potential of these membranes for the filtration of NP from water, mainly because of their tunable pore size, very high permeability, and ability to produce nanofibers in an easy and cost-efficient way by electrospinning. Moreover, they can be proposed for the promising system recovery of valuable nanomaterials from complex matrices.

\section{Conflict of Interests}

The authors declare that there is no conflict of interests regarding the publication of this paper.

\section{Acknowledgment}

The financial support of this work was provided by European Community's Seventh Framework Programme (FP7/20072013) under Grant Agreement no. 247899 of the project named NANOPOLYTOX. 


\section{References}

[1] "Project on Emerging Nanotechnologies," http://www.nanotechproject.org/inventories/consumer/.

[2] R. Brayner, "The toxicological impact of nanoparticles," Nano Today, vol. 3, no. 1-2, pp. 48-55, 2008.

[3] V. L. Colvin, "The potential environmental impact of engineered nanomaterials," Nature Biotechnology, vol. 21, no. 10, pp. 1166-1170, 2003.

[4] P. I. Dolez, N. Bodila, J. Lara, and G. Truchon, "Personal protective equipment against nanoparticles," International Journal of Nanotechnology, vol. 7, no. 1, pp. 99-117, 2010.

[5] R. S. Barhate and S. Ramakrishna, "Nanofibrous filtering media: filtration problems and solutions from tiny materials," Journal of Membrane Science, vol. 296, no. 1-2, pp. 1-8, 2007.

[6] D. Aussawasathien, C. Teerawattananon, and A. Vongachariya, "Separation of micron to sub-micron particles from water: electrospun nylon-6 nanofibrous membranes as pre-filters," Journal of Membrane Science, vol. 315, no. 1-2, pp. 11-19, 2008.

[7] A. Greiner and J. H. Wendorff, "Electrospinning: a fascinating method for the preparation of ultrathin fibers," Angewandte Chemie, vol. 46, no. 30, pp. 5670-5703, 2007.

[8] D. Li and Y. Xia, "Electrospinning of nanofibers: reinventing the wheel?" Advanced Materials, vol. 16, no. 14, pp. 1151-1170, 2004.

[9] C. J. Luo, S. D. Stoyanov, E. Stride, E. Pelan, and M. Edirisinghe, "Electrospinning versus fibre production methods: from specifics to technological convergence," Chemical Society Reviews, vol. 41, no. 13, pp. 4708-4735, 2012.

[10] M. Inagaki, Y. Yang, and F. Kang, "Carbon nanofibers prepared via electrospinning," Advanced Materials, vol. 24, no. 19, pp. 2547-2566, 2012.

[11] S. N. Arshad, M. Naraghi, and I. Chasiotis, "Strong carbon nanofibers from electrospun polyacrylonitrile," Carbon, vol. 49, no. 5, pp. 1710-1719, 2011.

[12] J. Sutasinpromprae, S. Jitjaicham, M. Nithitanakul, C. Meechaisue, and P. Supaphol, "Preparation and characterization of ultrafine electrospun polyacrylonitrile fibers and their subsequent pyrolysis to carbon fibers," Polymer International, vol. 55, no. 8, pp. 825-833, 2006.

[13] B.-H. Kim, K. S. Yang, Y. H. Bang, and S. R. Kim, "Thermally induced porous carbon nanofibers for electrochemical capacitor electrodes from phenylsilane and polyacrylonitrile blend solutions," Materials Letters, vol. 65, no. 23-24, pp. 3479-3481, 2011.

[14] B.-H. Kim, K. S. Yang, and H.-G. Woo, "Thin, bendable electrodes consisting of porous carbon nanofibers via the electrospinning of polyacrylonitrile containing tetraethoxy orthosilicate for supercapacitor," Electrochemistry Communications, vol. 13, no. 10, pp. 1042-1046, 2011.

[15] M. Wu, Q. Wang, K. Li, Y. Wu, and H. Liu, "Optimization of stabilization conditions for electrospun polyacrylonitrile nanofibers," Polymer Degradation and Stability, vol. 97, no. 8, pp. 1511-1519, 2012.

[16] F. Cengiz and O. Jirsak, "The effect of salt on the roller electrospinning of polyurethane nanofibers," Fibers and Polymers, vol. 10, no. 2, pp. 177-184, 2009.

[17] S. K. Nataraj, K. S. Yang, and T. M. Aminabhavi, "Polyacrylonitrile-based nanofibers-a state-of-the-art review," Progress in Polymer Science, vol. 37, no. 3, pp. 487-513, 2012.

[18] N. T. Hieu, J. Suk, D. W. Kim, O. H. Chung, J. S. Park, and Y. Kang, "Kang Silicon nanoparticle and carbon nanotube loaded carbon nanofibers for use in lithium-ion battery anodes," Synthetic Metals, vol. 198, pp. 36-40, 2014.

[19] A. Ramos, I. Cameán, and A. B. García, "Graphitization thermal treatment of carbon nanofibers," Carbon, vol. 59, pp. 2-32, 2013.

[20] K. Yoon, B. S. Hsiao, and B. Chu, "Functional nanofibers for environmental applications," Journal of Materials Chemistry, vol. 18, no. 44, pp. 5326-5334, 2008.

[21] A. Jena and K. Gupta, "Pore volume of nanofiber nonwovens," International Nonwovens Journal, vol. 14, pp. 25-30, 2005.

[22] H. W. Liang, L. Wang, P. Y. Chen et al., "Carbonaceous nanofiber membranes for selective filtration and separation of nanoparticles," Advanced Materials, vol. 22, no. 42, pp. 4691-4695, 2010.

[23] X. B. Ke, H. Y. Zhu, X. P. Gao, J. W. Liu, and Z. F. Zheng, "Highperformance ceramic membranes with a separation layer of metal oxide nanofibers," Advanced Materials, vol. 19, no. 6, pp. 785-790, 2007.

[24] J. Lin, B. Ding, J. Yang, J. Yu, and S. S. Al-Deyab, "Mechanical robust and thermal tolerant nanofibrous membrane for nanoparticles removal from aqueous solution," Materials Letters, vol. 69, pp. 82-85, 2012.

[25] X. Chen and S. S. Mao, "Titanium dioxide nanomaterials: synthesis, properties, modifications and applications," Chemical Reviews, vol. 107, no. 7, pp. 2891-2959, 2007.

[26] F. Gottschalk, T. Sonderer, R. W. Scholz, and B. Nowack, "Modeled environmental concentrations of engineered nanomaterials $\left(\mathrm{TiO}_{2}, \mathrm{ZnO}, \mathrm{Ag}, \mathrm{CNT}\right.$, fullerenes) for different regions," Environmental Science and Technology, vol. 43, no. 24, pp. 92169222, 2009. 

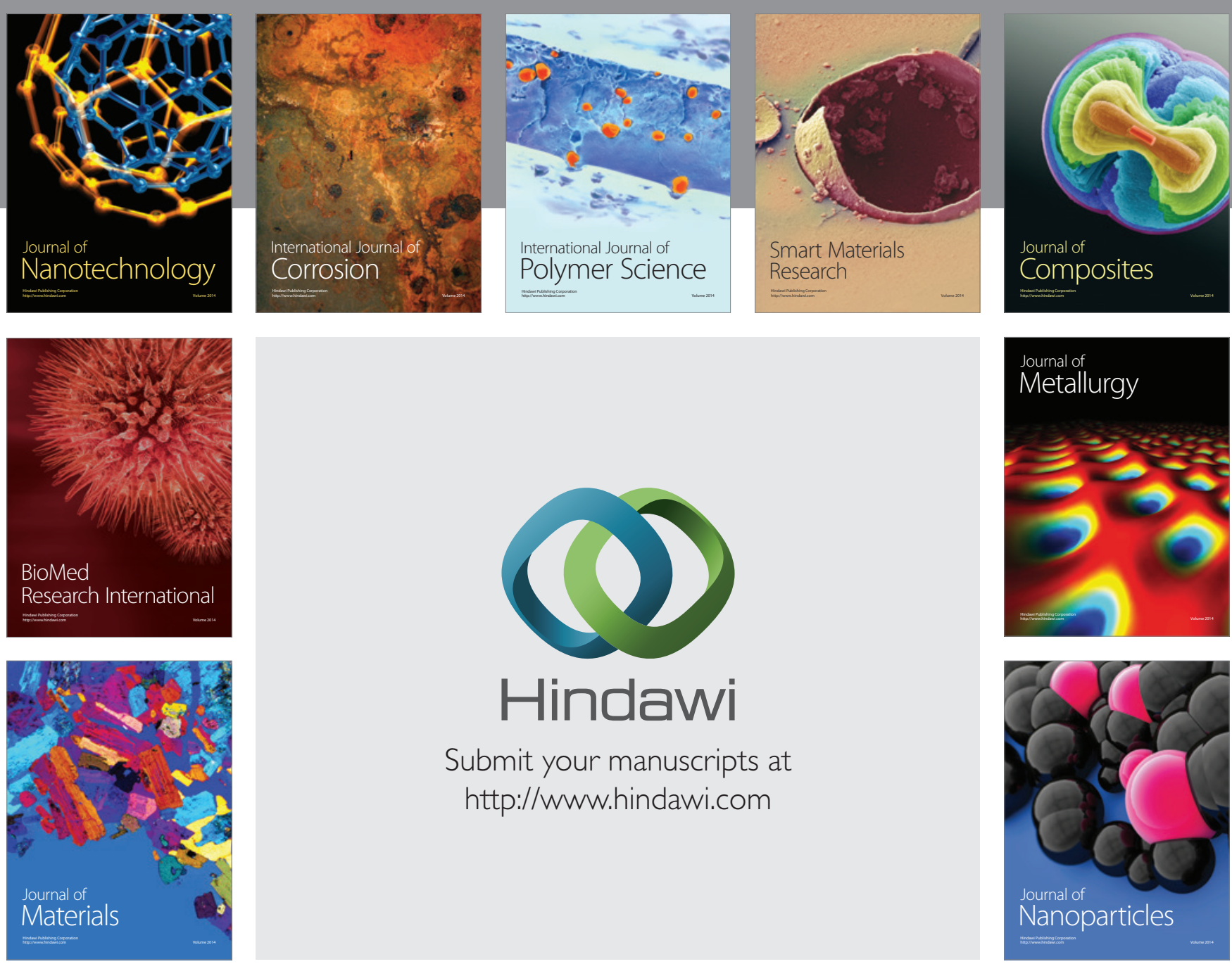

Submit your manuscripts at http://www.hindawi.com
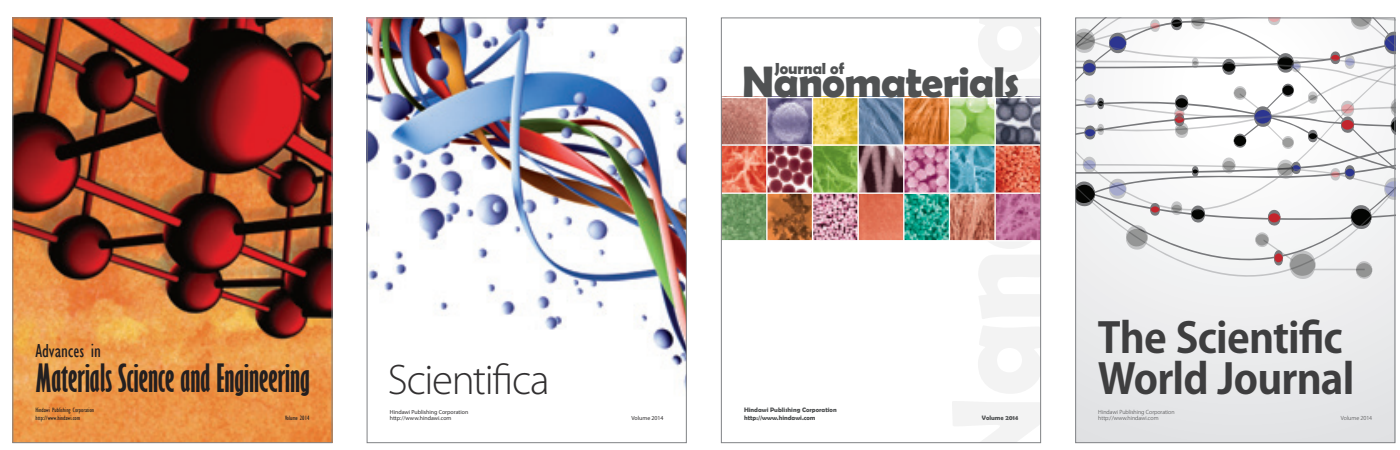

\section{The Scientific World Journal}
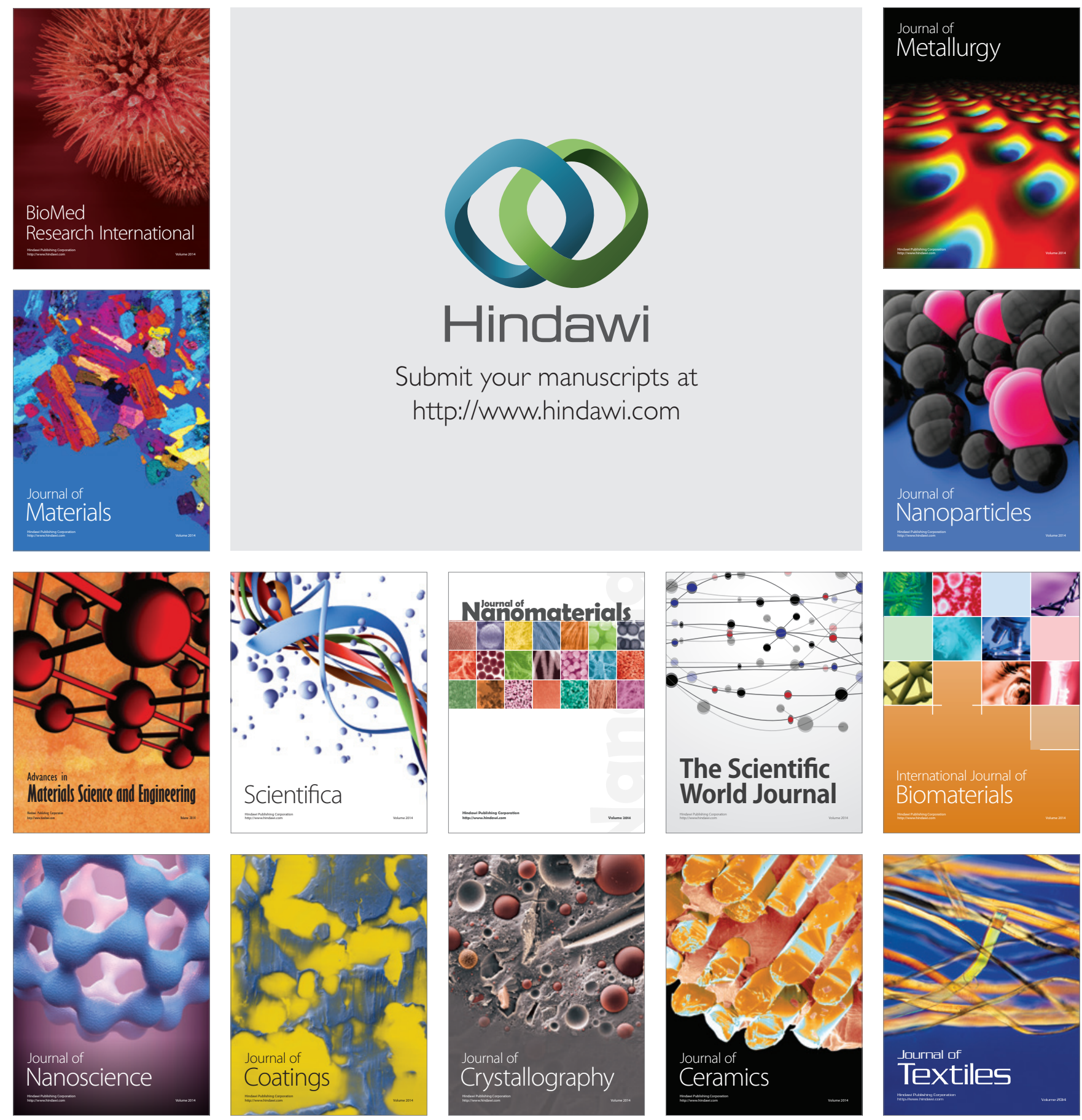